\title{
Arbor
}

\section{The Museum of the History of Science, Oxford}

\section{Jim Bennett}

Arbor CLXIV, 647-648 (Noviembre-Diciembre 1999), 435-444 pp.

\section{The Museum and its Building}

The Museum of the History of Science is a department of the University of Oxford within the Faculty of Modern History. It is currently undergoing a major redevelopment which involves the refurbishment of all the existing galleries and the building of new accommodation. It will reopen to the public in September 2000, with new displays in the permanent galleries and a new special exhibition gallery. Included in the remainder of the new accommodation are a library, a climate-controlled store, an education room and new facilities for staff and visitors.

Since its foundation in 1924, under the first Curator, Robert T. Gunther, the Museum has been accommodated in the Old Ashmolean Building, gradually advancing its acquisition of all floors. This building is of outstanding significance for the history of museums and the history of science. It was erected between 1679 and 1683 to house the collections presented by Elias Ashmole to the University of Oxford, his own and those of the Tradescant family. In the 19th century the expanded collections were distributed between the new University Museum (the natural history collections), the Pitt Rivers Museum (of anthropology) and the new building for the Ashmolean Museum (of art and archaeology).

The Old Ashmolean Building is the first building designed as a museum in Britain. Indeed for many years "the Museum" in English referred simply to this building in Broad Street, and the use of this Oxford- 


\section{Jim Bennett}

Latin title was what added the word "museum" to the English language. It may seem an extravagant claim, but we can go further and say that it is not clear that an earlier purpose-designed museum building can be identified in the world.

The building remains relatively unchanged, with three galleries and the original staircase between the entrance and upper floors. The building is testimony to the different concept of a museum in the seventeenth century -in some ways more active in the creation of knowledge-, and as active in its dissemination, as the modern institution. The basement floor was a chemical laboratory, the "Officina Chimica", indeed the first laboratory in a public building in England. Initially, for reasons of safety, there was no internal staircase between the basement and the floor above. The entrance gallery was a room for teaching and demonstration, while the top floor was the museum gallery in our sense and displayed the collection. Several smaller rooms (which also survive relatively unchanged) housed the original Ashmolean library.

The building thus represents a complete institution for experimental and natural historical knowledge in the 17th century a kind of "Solomon's House" as envisaged by Francis Bacon and later by the Royal Society. Indeed in its general arrangement it resembles the proposals made by Christopher Wren for a "college" for the Royal Society of London in 1678 (which was never built). Experiment belonged in the basement, dissemination through teaching in the middle floor, and organization, taxonomy and display above. As the first museum gallery, this unspoilt room at the top of the building with its tall windows, has a unique importance in museum history.

The activities within this building prior to the current redevelopment included a programme of special exhibitions and associated publication, and an expanding public programme has attracted many more visitors, whose numbers have more than doubled in recent years. The website is another area of development, and includes on-line versions of current and former special exhibitions. On the academic side, the Museum has the function of a university department and organises a programme of lectures and seminars. One of the most prominent ingredients in the academic life of the Museum is a graduate course leading to the degree of Master of Science. This is a one-year course in, to give it its full title, "History of Science: Instruments, Museums, Science, Technology", and is essentially a history of science course taught through a collection of instruments and apparatus and in the context of a museum. In each of the three years it has been running, it has attracted an international group of students. 


\section{The Museum of the History of Science, Oxford}

Other recent activities have included a collaborative documentation project with the Museo di Storia della Scienza, Florence, the Museum Boerhaave, Leiden, and the British Museum, London. With financial support from the European Commission, a combined database, rich in text and images, of instruments made prior to 1600 has been assembled and is available to the public in the four collaborating museums. It is hoped that it will be possible to make it more widely available by means of the internet.

\section{The Collection}

The Museum of the History of Science is especially famous for its outstanding collection of early instruments. This is especially true of mathematical instruments up to the end of the seventeenth century. The term "mathematical instruments", though correct for the period, can be misleading if it seems to indicate only devices for calculation and drawing. Rather it includes instruments for astronomy, navigation, surveying, dialling, gunnery, architecture, and other practices related to geometry. Before the introduction of the telescope and microscope at the beginning of the seventeenth century, these "mathematical" instruments represent the only class of scientific instrument, and in this area the Museum's collection is outstanding.

The astrolabe is generally placed among the most admired of scientific instruments, evocative of astronomy in the medieval and renaissance periods and common to both Islamic and Western science. The largest collection of astrolabes in the world belongs to the Museum of the History of Science; there are over 150 . The Oxford collection is strong in both Islamic and Western instruments and, while early astrolabes are so rare that each has individual interest, there are a number of outstanding examples.

The Western astrolabes go back to the 13th century, represented by three instruments; there are 6 from the 14th century, one of them exactly resembling the astrolabe described by Chaucer. One of the 15th-century examples is particularly noteworthy for having an equatorium (an instrument for calculating the positions of planets) on the reverse, and is thus one of only a small handful of extant metal equatoria. The Museum also has a late 15th-century quadrant with a different type of equatorium (a sexagenarium) on the reverse. Each of the astrolabes will have some point of interest for a specialist, but highlights among the later Western instruments are an astrolabe belonging to Elizabeth I, made by Thomas Gemini (generally regarded as the first commercial instrument maker in 


\section{Jim Bennett}

England) in 1559; outstanding examples of the work of the Flemish school of the 16th century, represented by Arsenius and Coignet; arguably the finest surviving Italian astrolabe, signed in 1580 by the cosmographer to Cosimo de' Medici, Egnatio Danti; and a magnificent large instrument by Erasmus Habermel, one of the finest instruments made by this famous maker in the service of Emperor Rudolph II in Prague.

Among the Islamic astrolabes is an instrument dated to the 9th century, probably the oldest astrolabe in the world, and the only complete spherical astrolabe, which dates from the 15th century. The earliest known Persian astrolabe is present and dates from the late 10th century (bearing the date 984, it is, in fact, one of the earliest dated instruments in existence), as well as an Islamic astrolabe owned by Archbishop Laud. One outstanding Persian astrolabe from the early 13th century has a geared calendar movement and represents an important step in the prehistory of the mechanical clock.

The collection of 12 early armillary spheres comprises rare and important Italian, Flemish and English instruments, including one of the earliest extant examples - an Italian instrument from around 1500and a very large sphere from around 1580 , which belonged to Henry Percy, "The Wizard Earl». This collection - large in view of the rarity of such instruments - is complemented by approximately sixty globes and orreries, roughly equally divided between European and non-European. An example from the latter group is an Indian «bhugola" from 1571, one of the very few dated Indian pieces from the period. Of outstanding importance among the orreries is the earliest English example of the instrument, made in silver and ebony by Thomas Tompion and George Graham in about 1710 .

The collection contains some thirty early horary quadrants and forty nocturnals. Again these figures are large and represent the largest extant collections in each case. The quadrants are both Western and Islamic. A particularly rare example is an English quadrans vetus from the 14th century. Of comparable rarity, that is, only three or four examples are known, is the rectilinear sundial related to the horary quadrant and known as a naviculum; the example in Oxford dates from the 15th century. The quadrants range from the 14 th to the 18 th century, and the nocturnals from the 16th to the 18th. Outstanding in the latter class are German and Flemish examples from the 16th century.

The sundials in general form a collection of extraordinary and quite outstanding range and depth, having some 750 examples. This is the world's largest and finest collection of early dials. The collection begins, in chronological terms, with a unique portable Roman dial from around 


\section{The Museum of the History of Science, Oxford}

A. D. 250, and it is international in scope, ranging over all types and periods, as well as all significant manufacturing traditions.

As an example of an important sub-group within the collection of dials, there are 140 diptych dials, most in ivory from the workshops of Nuremberg in the 16th and 17th century. A recent addition is the earliest known English instrument of this type. Again this is the world's finest collection in this important class. Another example is the group of 64 equinoctial ring dials, including three of the very rare "astronomer's rings" related to this type of dial. This instrument was invented by Gemma Frisius and one example at Oxford is from the workshop of his nephew Walter Arsenius in Louvain where they were first made; it is dated 1567. Another was made in 1600 for Albert VII, Archduke of Austria, and his wife Isabella Clara Eugenia, who together ruled the Spanish Netherlands from 1599.

The sundial collection includes a polyhedral dial of around 1520 bearing the arms of Cardinal Wolsey, probably made by Nicholas Kratzer, astronomer to Henry VIII, and the earliest known signed and dated English dial, made in 1542 by Nicholas Oursian, clockmaker to Henry VIII. Among unusual examples is a chalice dial of 1599 , that is one having the gnomon and hour-lines inside a gilt drinking cup, and a 16th-century dial with the hour lines on the inner surface of a gilt spoon.

The sundials, horary quadrants, nocturnals, \&c, are complemented by the clever and elaborate compendia, where several such devices are combined in a single instrument. The Museum has a number in the strong German tradition of such pieces, by Schissler, Habermel, Schniep, \&c, but also from other Continental centres -one, for example, by the famous Philippe Danfrie in Paris - and several from London.

Also well represented are early surveying instruments and artillery instruments, both for setting a gun and for finding the range of the target, are in the Museum. These include instruments by the famous 16thcentury maker in Prague, Erasmus Habermel, such as an elaborate gun sight, a rare water level on a tripod, a triangulation instrument, a plane table alidade, two altazimuth theodolites and a military protractor for fortification work. If we add such other instruments as a compendium, an astrolabe and several sundials, the Museum has the largest collection in the world of instruments by this celebrated maker, and can demonstrate his outstanding ability to produce beautiful, gilt pieces that are among the finest instruments ever made and remain among the most prized by specialist collectors.

Also in surveying the Museum has one of the most celebrated among all early instruments, the highly decorated gilt geometrical quadrant by Christopher Schissler, with relief scenes of surveyors in action; only one 


\section{Jim Bennett}

other example exists, in a German collection. Another highlight is a triangulation instrument by the inventor Joost Bürgi, who worked for Wilhelm IV in Kassell, Rudolph II in Prague, Tycho Brahe and Johannes Kepler. Also among the surveying instruments is the earliest known Irish instrument of any type, a circumferentor made in Dublin in 1667, and the earliest English theodolite, as altazimuth instrument of 1586 by Humphrey Cole (the similar instrument at the National Maritime Museum has a slightly earlier date, but is of doubtful integrity).

The large range of calculating and drawing instruments complements those for surveying and the military arts, since many of them are for related tasks. They include an example of the earliest form of logarithmic slide rule, c.1634, and Samuel Morland's adding machine of 1666 . There are sectors and rules specially for surveyors, gunners, architects and navigators. Sets of drawing instruments include what is probably the first English example - by Elias Allen, c.1625 - and a very fine Italian set from the early 16 th century.

The collection of navigation instruments includes such rarities as a mariner's astrolabe and a wooden traverse board, as well as a good range of backstaves, compasses, octants and sextants. Another maker who should be given particular mention is Humphrey Cole, generally understood to have been the first English instrument maker. One of the largest collections of his work is in the Museum.

The Museum also displays the remains of the earliest extant English observatory instruments. These are three measuring instruments used by the Savilian Professors of Astronomy in the 17th century, a very large quadrant and sextant, and a smaller quadrant adjustable by rackwork; one was signed by Elias Allen in 1637. These pre-date the foundation of the Royal Observatory at Greenwich and, leaving aside the possible use of prehistoric monuments for astronomy, are the earliest surviving instruments from an observatory in Britain.

The microscopes form a collection of international importance, representative of the history of the light microscope. It incorporates two major collections: that of R.S. Clay, the historian of the microscope, formed along deliberately historical lines, and the Royal Microscopical Society's collection, formed initially as a working and contemporary collection from its foundation in 1839. The Society was interested in having the finest representatives of the progress in instrumentation, so its collection is rich in the nineteenth-century masterpieces that particularly characterized British manufacture during this period. These two collections are in addition to the Museum's general collection acquired from miscellaneous sources. 


\section{The Museum of the History of Science, Oxford}

The microscopes go back to the seventeenth century, and include, for example, among early attributable pieces, four microscopes by John Marshall and over a dozen by Edmund Culpeper. The eighteenth-century models are very well represented, and include the large and extravagant silver microscope made by George Adams for George III in about 1770 . There are about 450 items in the collection of the Royal Microscopical Society (of which over 300 are microscopes and the rest unassociated accessories and other tools for microscope work), a further 300 microscopes from the Clay Collection, and over 200 in the Museum's general collection.

There is also a fine collection of early telescopes, again going back to English makers of the seventeenth century, including one signed by John Yarwell. They include the most complete range of the work of the specialist in reflecting telescopes, James Short, a 12 -ft reflector by him being the only surviving example at this size and, made in $\mathbf{1 7 4 2}$ for the Duke of Marlborough, the first attempt to make a really large reflector, the instrument that has become so important for the development of astronomy. There is also a 7 -ft Newtonian reflector by William Herschel. In refractors, the Museum has a number of early instruments by the Dollond family, who introduced the fundamental technical advance of achromatic lenses.

Some 60 telescopes are complemented by such other optical instruments as camera obscuras, graphic aids, a fine collection of monocular opera glasses and a large collection of early spectacles. Among the other optical instruments such as spectroscopes and polarimeters. There are around 800 items of photographic equipment in all, of which there are some 150 cameras and a similar number of lenses, while the remainder are accessories such as shutters, exposure guides and meters, processing equipment, projectors and slide viewers. Certain items belonged to well known personalities, such as the three astronomical cameras made for the amateur astronomer Warren de la Rue for photographing the moon in the 1850s (the Museum also possesses several glass slides of the moon taken at the time), the wet collodion photography outfit of the Reverend Dodgson (Lewis Carroll), and the archaeological camera made in 1910 for T.E. Lawrence. The entire historical spectrum of photography is covered from Daguerre in 1839 to the Polaroid camera of the late 1940s. A few of the collection's more important items are a Dubroni "portable darkroom" camera of c. 1865, several detective or concealed cameras such as Marion's metal miniature camera of 1888 which used the new dry-plate gelatin-based film, the "Naturalist" camera of c. 1881 with rack-and-pinion plate-changing mechanism, a Sutton panoramic camera with water- 


\section{Jim Bennett}

filled lens, and a series of Eastman-Kodak "Bulls-Eye» cameras of c. 1896 and later box cameras that heralded "photography for the masses". The range of lenses is also quite comprehensive, from the singlet landscape as used by Daguerre and the early doublet and Petzval-type lenses, triplet lenses, early convertible lenses, to the more recent lenses by Zeiss and others.

Observatory instruments of the eighteenth-century are well represented by the foundation instruments of the Radcliffe Observatory, dating from 1773. These comprise a large and impressive 8-ft mural quadrant, a 12 -ft zenith sector, a transit instrument and an equatorial sector, together with the regulators (precision clocks) required to time the observations. What is particularly important about these instruments is that they represent a complete set of state-of-the-art astronomical instruments of English design (all designed by George Graham) and all by a single maker, the finest astronomical instrument maker of the time, John Bird. The director of the new observatory, Thomas Hornsby, was determined to obtain equipment of the highest standard and this determination came at a significant epoch, when London makers were the best in the world and when their exported instruments were determining an international consensus for observatory measurement. All of this makes the set of instruments at Oxford particularly significant for the history of astronomy. A number of the Radcliffe's later instruments are also in the Museum, notably the 1838 mural circle by Thomas Jones.

These fixed instruments are complemented by portable ones, such as a quadrant by Bird, equatorial instruments and telescopes on stands. An important group of 71 instruments from the Royal Astronomical Society's former collection represents not only portable astronomy but the related and increasingly important technology of geodesy, especially from the early 19 th century.

An interesting and unexpected acquisition with the Radcliffe material was a collection of material relating to the 18th-century artist and amateur astronomer John Russell, R.A, Painter to George III. This includes a large, 1.5 metre diameter pastel drawing of the moon from 1795 (the result of a decade of observation and measurement), an album containing 180 pages of mounted sketches of the moon, 1764 to 1805 , rare examples of Russell's printed lunar planispheres and lunar globe, with uncut printed gores for the latter, and other printed and manuscript material.

In the eighteenth century, particularly in England, natural philosophy became a fashionable pursuit and individuals began to form private collections of instruments and demonstration apparatus. The most famous collection of this sort is that of George III, now at the Science Mu- 


\section{The Museum of the History of Science, Oxford}

seum in London, but the Museum of the History of Science has a very significant predecessor, in fact the earliest surviving English cabinet of instruments. This was assembled by Charles Boyle, 4th Earl of Orrery, who died in 1731. Most of the instruments date from the early years of the 18th century and together they represent the expansion of instrumentation from mathematics to optics and experimental philosophy. There are 68 pieces in all, a quarter of them signed by the London instrument maker John Rowley (the best collection of this important craftsman's work). The pieces by Rowley include an exquisitely made silver armillary sphere and, by contrast, a brass steelyard of unprecedented accuracy.

The Museum also has a fine collection of lodestones; comprising some twenty-two items, it is the only collection of such a size in Europe. The large and famous lodestone of 48 ins diameter, presented to the Ashmolean Museum by the Countess of Westmorland in 1756, is the most spectacular item, with its original mahogany case and mount, and gilt ducal coronet.

Chemical glassware, anonymous and fragile, has rarely been the object of connoisseurship and active collecting. However, chemistry is strongly represented in the museum by a collection centred around early 19th-century items associated with the Oxford professor, Charles Daubeny. Pre-19th century chemical artefacts are extremely rare but the collection includes examples inherited from Daubeny's 18th-century predecessors. This collection has the added interest that much of it was used in the gallery of the museum where it is now displayed, which was the University's chemical laboratory until 1847.

Among other important chemical instruments are a kit designed by Sir Humphrey Davy for soil analysis, and a 16-in. burning lens made (again for use in its present site) in 1791; a comparable (Joseph Priestley's) survives in America. A significant medical collection is complemented by an extensive and important collection of early ceramic drug jars.

The collection of clocks has important examples dating back to the sixteenth century and the Museum contains examples of the work of such figures as Tompion, Graham, Quare, Knibb and Shelton, as well as one of the earliest longcase clocks by Fromanteel from the 1660s. There is an important collection of early turret clocks and the most extensive collection of clocks made in Oxfordshire.

Nineteenth-century physics, particularly electricity, forms an important collection, but the twentieth-century material is much more selective and consists only of outstanding items associated with Oxford. Most notable are the equipment for X-ray spectrometry with which Moseley established atomic numbers (c.1914), and some of the equipment used to 


\section{Jim Bennett}

444

develop penicillin into an effective drug (in 1940) -experiments fundamental to modern chemistry, nuclear physics and quantum physics in the first case, and to modern medicine and public health in the second. Similarly, one of the most popular exhibits with the visiting public is the blackboard used by Albert Einstein during a lecture in Oxford in 1931 and still bearing his chalked equations.

The collection of early photographs is of outstanding importance. It contains about 15,000 photographic images of all types. Among the very earliest material are about 50 daguerreotypes, a similar number of calotypes and about 500 experimental photogenic drawings by John Herschel, dating from between 1839 and 1843. Among other early photographers represented are Antoine Claudet, John Ruskin and William Henry Fox Talbot. There are also about 1,000 images on glass using early colour processes (1890s-1930s). These photographs are both a unique visual archive and primary material for the study of the history of photographic science.

The Library is based on the collection of 1,100 volumes in the antiquarian collection donated to the Museum by Lewis Evans, a great many of them rare foreign printings of the sixteenth and seventeenth centuries. They form the core of a unique specialist library on the history of scientific instruments that has now grown to some 13,000 books, about half of which are pre-1850. This is supplemented by a pamphlet collection of about 5,000 loose items and some 300 bound volumes. There is an archive of scientific manuscripts and a collection of prints (engravings, etc), which runs to some 2,000 items and is especially strong for the period between 1650 and 1850 .

The collections comprise, for the most part, scientific instruments of different types, but from a period when the idea of natural knowledge was different from the science of today. The museum's significance lies in its potential for adding historical and cultural dimensions to our understanding of science, for moving beyond the idea that curiosity is satisfied by appreciating how things work in modern terms. It therefore offers a more holistic view, where scientific understanding is enriched by insights more characteristic of the humanities. 